\title{
Research on the Demand of Library Mobile Information Service and System Design in Information Age
}

\author{
Li Guo \\ Xi'an Aeronautical Polytechnic Institute, Library, Xi'an, Shaanxi, 710089
}

Keywords: information age; library mobile service demand; system design

\begin{abstract}
With the advent of the information age, Internet and mobile communication technologies have been widely used. The application of mobile information services involves various fields of social life, which has greatly changed the way people produce and live. The application of mobile information services in the library field and the innovative construction of the library service model, enable the library to provide services for users anytime and anywhere, which is the focus of this paper. Based on the analysis of the status quo of mobile information service and the demand of mobile information services in China, this paper discusses the design strategies of library mobile information service system in information age, and provides feasible suggestions for solving the current library service problems in China.
\end{abstract}

\section{Introduction}

With the advent of the digital information era, people have more and more access to information. The convenient service model of mobile Internet has greatly impacted the traditional library service model, and the service model of the library is facing major changes. Therefore, the introduction of wireless information network technology into the field of library services, making the library's services more convenient, in this context, the new mobile library service model came into being. With the help of mobile information technology, mobile libraries can break through the boundaries of time and space and develop various mobile terminal devices through innovation, so that they can review library collections anytime and anywhere. Since the reform and opening up, the living standards of our people have improved remarkably, the spiritual outlook of the people has also been greatly changed, and the demand for spiritual culture has become higher and higher. In order to meet people's growing spiritual and cultural needs, libraries that provide reading services must break the traditional service model, explore the system design of library mobile information services, effectively integrate mobile information technology, and integrate library and mobile Internet resources. Improve the efficiency of library services.

\section{The Status Quo and Problems of Library Mobile Information Service}

The development of library services in China Since the application of mobile information services, there are SMS services and Wap website services, which enable users to read information through mobile phones, computers, tablets, etc., to meet the needs of users [1]. Before the popularization of smart phones and mobile Internet technologies, China's library mobile information services were mainly realized through SMS notification. With the mobile Internet technology and smart phones entering people's daily lives, library mobile information services began to pass Wap website services. The channel provides reading services, and in recent years, with the promotion of Weibo, WeChat, etc., more young people can also learn real-time information through new media platforms such as Weibo. The current development of library mobile information services is still in its infancy. The current mobile information services provided by libraries mainly include borrowing library management, recording user information, library announcement information, etc., and then Weibo is applied to library mobile information services. The content of the library mobile information service has been enriched, and the promotion process of the library mobile information service has been continuously deepened, and the scope of the 
library's service has also been expanded.

With the popularization and application of mobile Internet technology, the library's mobile information service has achieved remarkable results. However, there are still many problems in the library mobile information service, which restricts the full play of the library cultural service function. At present, China's library mobile information service problems are mainly manifested in the following aspects: (1) mobile information services account for a low proportion of total library services. According to relevant data, as of 2017, mobile information services accounted for nationwide. The proportion of total library services is $42.3 \%$, and the geographical distribution of mobile information services is large, and regional development is extremely unbalanced [2]. (2) The promotion of library mobile information service is backward. At present, the application of mobile information service in library in China is obviously lagging behind the expansion of mobile information service. The lack of understanding of mobile information service by library users is not conducive to the library mobile information service. (3) The problem of formalization of mobile information service content. In most library mobile information services, knowledge simply digitizes library collections, and does not fully utilize the advantages of mobile information technology, and cannot achieve retrieval, reading, commenting, and decision making. (4) At present, the service content of China's library mobile information service still stays at the stage of transactional service, which is restricted by factors such as book copyright and funding. In response to the above-mentioned problem of library mobile information services, effective measures must be taken to promote the development of mobile information services and give full play to the library's cultural service functions.

\section{Analysis on the Demand of Library Mobile Information Service}

The ultimate goal of library development of mobile information services is to fully meet the user's borrowing needs and improve the utilization of library collection resources. The premise of developing mobile information services should fully understand the needs of surveying library users, and through data analysis and investigation. The habits of library users, the services they are expected to provide, and suggestions for current library mobile information services. Therefore, according to the needs of users, effective countermeasures can be proposed and implemented to improve the utilization rate of mobile information service resources of libraries in China. Therefore, the following is the analysis of library mobile information service demand from the two aspects of time demand and space demand, combined with China's actual situation.

The time requirement of the library mobile information service can also be called the immediate demand, that is, the demand for accessing the library information generated by the user after being inspired by something or something in the daily social life or work process [3]. The main performances are as follows: First, some users who have already left campus life are based on the needs of the test. They hope to make full use of the piecemeal time after work, and meet the needs of reviewing the test materials through the mobile information service provided by the library; some users are learning or working, and hope to meet the needs of self-enhancement or leisure and entertainment through mobile information service functions. Third, users engaged in cultural-related businesses, in order to achieve convenient access to relevant professional materials, are also from mobile terminal devices. The time requirement of library mobile information service has obvious sudden and temporary characteristics, so it is also called instant demand, but we usually use the user's access to the library to be sudden and immediacy. Behavior, there are fewer ways to consult users in a planned way, so it can be said that time requirements are the main needs of library mobile information services.

The space requirement of library mobile information service can also be called geographic demand, which refers to the user's demand for navigation search of the library's geographical location and library collection materials [4]. Its main performance is as follows: On the one hand, some users have less knowledge of the library, so they have the physical location of the library, the traffic navigation route and the mobile information service needs of the surrounding basic service facilities; on the other hand, the library When users borrow books, they have a need for rapid 
retrieval of library collection materials and related usage navigation. Library space demand is less than time demand, but space demand is also an important part of library mobile information service needs, and can not be easily ignored.

\section{The Design Countermeasures of Library Mobile Information Service System in Information Age}

In the context of the information age, there are many ways to construct the library mobile information service system. However, the construction of the library mobile information service system in China should take into account all aspects of the factors, and build on the actual development of the library in China. Give full play to the library cultural service function of our country, meet the time and space needs of the masses for library mobile information services, and at the same time create a brand new user experience service to truly serve the people.

\subsection{Open Mobile SMS Push Service.}

The mobile SMS push service is slightly involved in the current mobile information service field of the library, but its application promotion is not deep, and the marketing advantage of the mobile SMS push service is not fully utilized. Mobile SMS push service is mainly divided into two ways, namely, personalized information customization service mode and interactive information service mode [5]. The personalized information customization service mode refers to customizing the library service according to the user's mobile information service demand, customizing the library reading service according to the user's preference and reading habits, pushing the new book to the user by SMS, and according to the book reservation, Borrow a personalized SMS reminder service for books. The interactive information service mode refers to the mobile communication service mode, which enables the user to edit the corresponding short message according to the standard of the library mobile short message service platform, thereby realizing the interactive information service, and the content includes the bibliographic retrieval, mobile reference, etc. of the library collection. However, due to the limitation of the number of words and format of the short message, the main body of the mobile short message service mode is the short message push service.

\subsection{Develop Library Mobile App Client.}

The development of mobile App client is a key investment project in various industries, because the mobile App client has obvious convenience advantages, and can be used by users on mobile terminal devices anytime, anywhere. The development of the library mobile App client is the most important project built by the library mobile information service model, which can maximize the library's mobile information service. Therefore, it is necessary to attach great importance to the development of the library mobile App client. The library mobile app client can be built by integrating LBS, QR, and AR network connection technologies, designing the module interface, menus, buttons, and prompt information of the App client to realize the library App client business function, thereby providing library users with mobile Internet service. It is worth noting that the development of the library mobile App client not only provides library users with access to services, but also pays attention to providing users with download services for related books. The key to the development of the mobile App client is to design the function to improve the user experience. For example, the design of the App client of Xi'an Jiaotong University Library, the innovation introduces the SMS push service into the function design, and realizes the query and book reading function of the user borrowing information. It also enables the promotion of library-related news and short-term reminder services.

\subsection{Build a Library Wap Website.}

The Internet Wap website that builds the library mobile information service can break the time and space restrictions of traditional libraries and build a Wap website that can be accessed anytime and anywhere using mobile devices such as smart phones and tablet computers. The construction of a fully functional Wap website can promote the library. Mobile information services are truly 
implemented. The construction of the library Wap website needs to pay attention to: on the one hand, by introducing the Wap network communication protocol in the library's mobile information service, the information resources and business functions in the Internet environment are equipped into the mobile terminal of the library, thereby making In the mobile Internet environment, it is not subject to the cost of network information transmission. On the other hand, the design of the library Wap website must be based on the actual situation of the library, to build a Wap website suitable for the library's own characteristics, in order to meet the needs of users to easily access the library's mobile information services on the Internet. The construction of the library Wap website should have the characteristics that the library mobile information service is rich in functions, convenient in operation and easy to be mastered by users, thus promoting the library Wap website to serve users anytime and anywhere. This is also the current library mobile information service mode. Apply a wider range of service models.

\subsection{Innovate Library Mobile Knowledge Navigation Service Model.}

The construction of convenient and humanized knowledge navigation of library collection materials can effectively change the current low usage rate in the use of libraries in China, reduce the difficulty for users to access library materials, and improve the utilization rate of library collection materials. To better play the library's cultural service function. The main strategies for the construction of library mobile knowledge navigation are as follows: First, the core idea of building is based on user experience, and the library mobile knowledge navigation service model is user-centered and constructs humanized knowledge navigation service. Secondly, the content construction of library mobile knowledge navigation mainly includes library book information, book information consultation, book navigation search and user service evaluation. Thirdly, the library mobile knowledge navigation service model should also be combined with subject librarians to use the $4 \mathrm{G}$ communication network technology and the library's original collection data advantages to lay the foundation for building a library mobile knowledge navigation service model. Finally, the innovation builds the library mobile alliance service model, and provides self-service navigation service mode according to the changes of user needs. Through the above measures, we will build an innovative library mobile knowledge navigation service model to better provide reading services for people and provide support for university discipline construction.

\section{Conclusion}

With the continuous development of society and the deepening of the application of science and technology information technology, people's lifestyles and reading habits have also undergone great changes. As a result, the demand for the use of libraries has also changed. People's mobile information services for libraries both time and space demand tend to be diversified, convenient, and personalized. Therefore, in order to meet the people's social production and living needs, the library pays attention to the development of mobile information service functions, builds a system of library mobile information service system, opens mobile SMS push service, develops library mobile App client, and builds library Wap website. Innovate the library mobile knowledge navigation service model, standardize the library mobile information service operating environment, meet the diversified needs of users, and further improve the utilization of library collection resources.

\section{References}

[1] Zhang Shuyuan. Research on the Construction Mode of Mobile Library Service Mode [J].Innovative Science \& Technology, 2017(07):89-91.

[2] Tang Yi, Wang Danxue. Research on the Construction of WeChat Public Platform of National Digital Culture Network [J]. Library, 2017(02): 102-107.

[3] Liu Yang, Sun Wei. Discussion on the Innovation of Library Mobile Service Demand in the 
Information Age [J]. New Campus (early), 2015(10): 168.

[4] Wang Hongyan, Yang Lizhe. Research on Library Information Service Based on WeChat[J]. Science \& Technology Innovation Review, 2015, 12(22): 229-230.

[5] Sun Gefei. Research on the Status Quo, Service Model and Development Countermeasures of Mobile Library in China[J].Journal of Library and Information Sciences, 2014, 32(01): 32-36+52. 